\section{Training courses at the old Silk Road city of Merv, Turkmenistan Tim Williams}

The Institute has a long association with the World Heritage Site of Merv, as reported in the first issue of AI (1997/1998) and in AI 2002/2003. Faced with major problems in recording the huge mudbrick structures and ensuring the survival of this fragile archaeological resource, the Institute and the Turkmenistan Ministry of Culture now have a series of training programmes to support the staff of the Ancient Merv Archaeological Park.

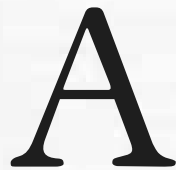

succession of cities at Merv, which together encompassed over 1000 ha, range in date from the fifth century to their decline after the Mongol sack in 1221 (Fig. 1). ${ }^{1}$ These cities, once one of thelargest urban centres in the world, were home to hundreds of thousands of traders, artisans, scholars and clerics, who prospered and travelled along the fabled silk routes that spanned half the globe. They now lie in dusty ruin: a monument to past civilizations and changes in world trade, politics and religion.

The Institute of Archaeology has had a long collaboration with the Turkmenistan Ministry of Culture, stretching back to 1991, when the former Soviet Central Asian Republic of Turkmenistan gained independence. Work originally focused on archaeological research, but more recently it has developed to explore approaches to the conservation and management ${ }^{2}$ of the Ancient Merv Archaeological Park, which since 1999 has been a World Heritage Site.

The Ministry of Culture, and especially their staff at the Archaeological Park at Merv, already have a great deal of expertise in dealing with the problems of managing the complex and fragile archaeological landscapes of Merv. Unfortunately, they are short of both essential equipment and infrastructure, and of the opportunity to work alongside colleagues from the international community in order to develop solutions to the massive conservation challenges that face Merv today, such as rising groundwater, looting and agricultural damage to the suburban areas.

As a result, training programmes have been developed to support the Archaeological Park staff in their efforts to manage the site. ${ }^{3}$ These were seen as one of the best ways to develop a sustainable collaboration between the park and outside agencies, and although the programme will not remove the need for international assistance, in terms of essential equipment or expertise, it is hoped that it will create a platform for a more equal exchange and development of knowledge and skills. We also believe that the development of local skills is best supported through the undertaking of practical projects, which, while making advances in the conservation of the archaeological and historic resources at Merv, also provide opportunities for the staff to see conservation management theories applied in practice. Looking beyond Merv, the aim is to develop a range of skills and infrastructure that are applicable to the problems of managing and researching the archaeological resource of the country as a whole.

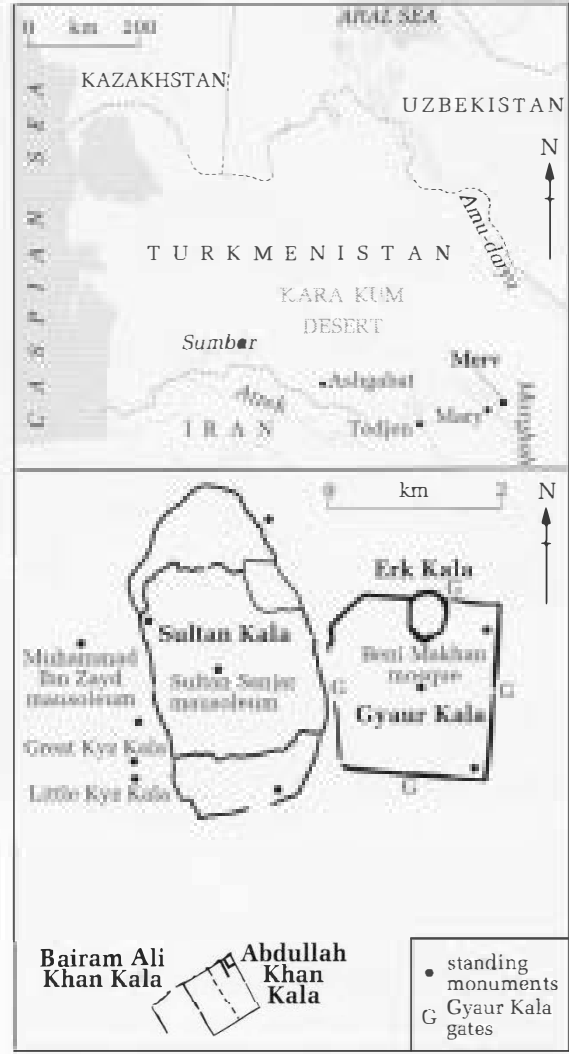

Figure 1 (Upper) The location of Mervin southern Turkmenistan and (lower) its ancient cities. The earliest city, Erk Kala, was founded c. 500. Around 280 it became the citadel for the much larger Hellenistic city of Antiochia Margiana (known today as Gyaur Kala). In the seventh or eighth century a new Islamic city, Sultan Kala. was built to the west, alt hough Gyaur Kala continued in use as an industrial suburb. In the early fifteenth century the Timurid city of Abdullah Khan Kala was constructed to the south, to which was added a suburb, Bairam Ali Khan Kala, probably in the eighteenth century.

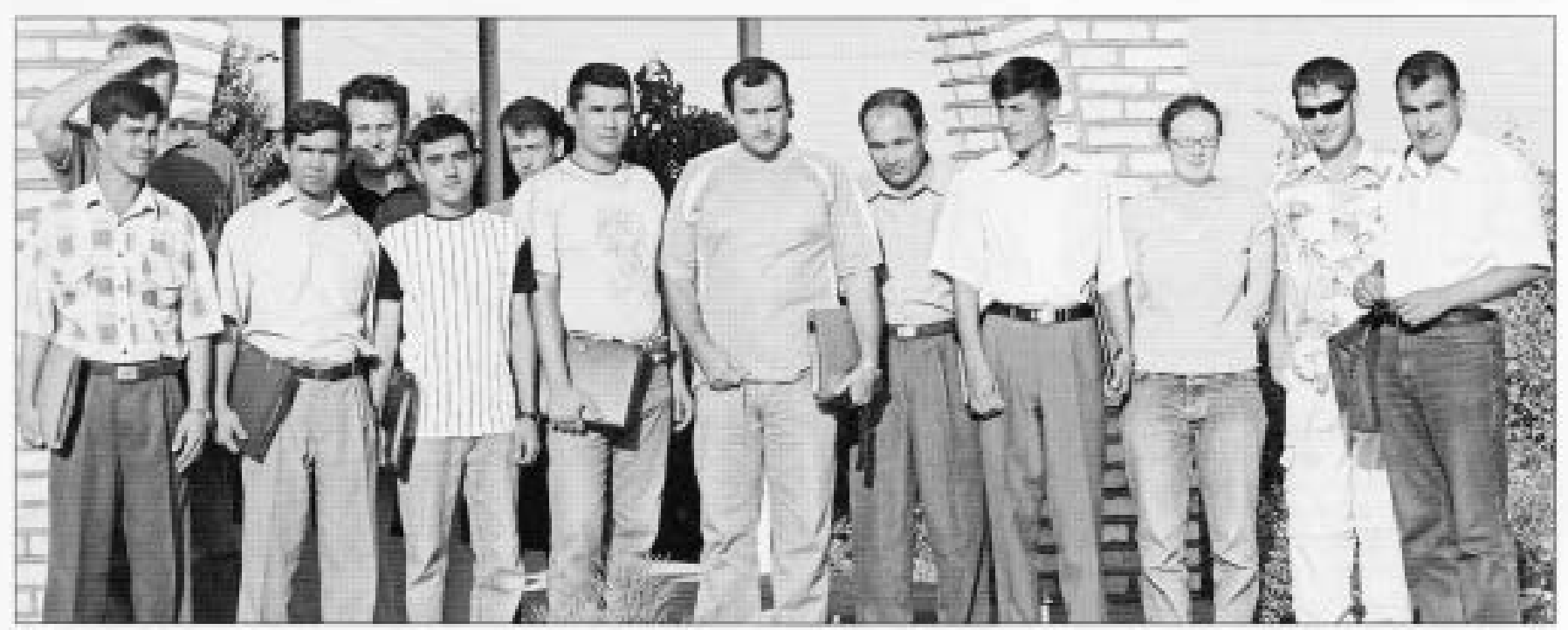

Figure 2 Participants in the training programme. 


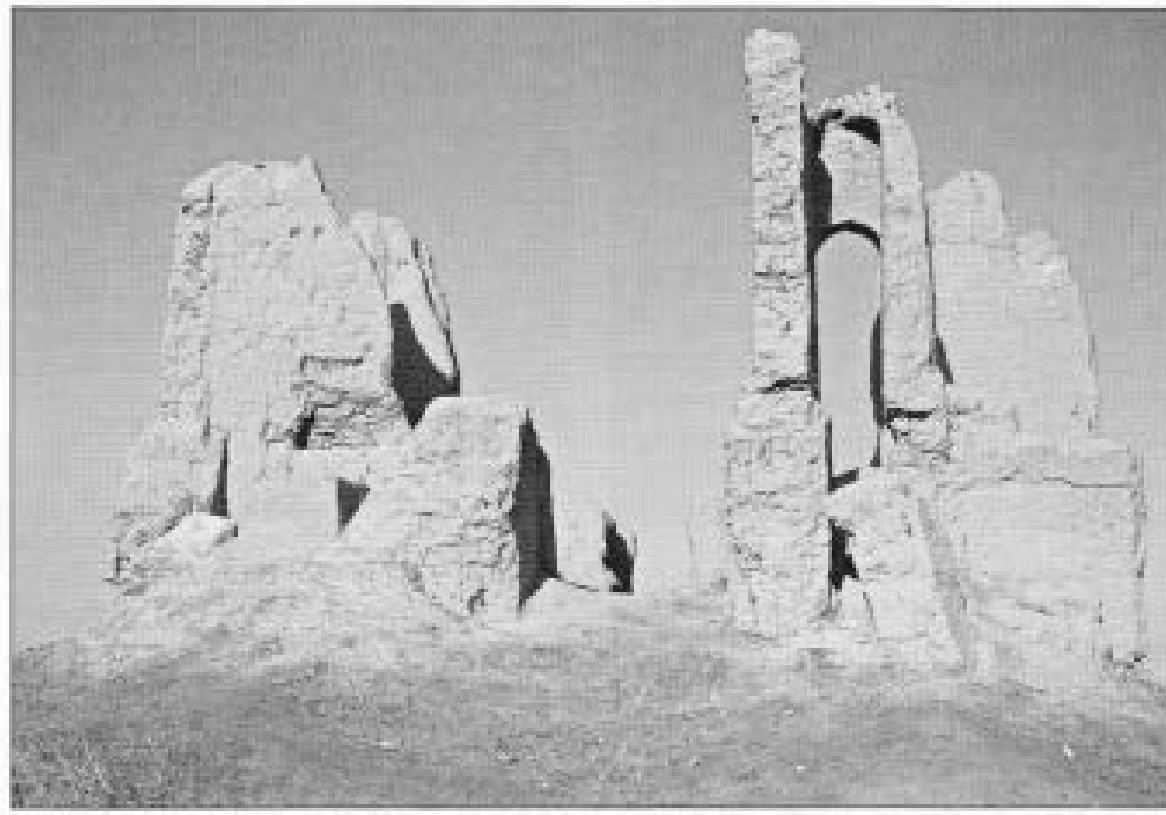

Figure 3 Porsy köshk, an example of one of the eroding elite houses, now abandoned for over 800 years.

\section{Training courses}

The approach to the training courses was to mix formal lectures with discussionbased seminars and practical work. The aim was to promote dialogue about approaches, not to suggest that all the answers to the conservation, documentation or research problems of Merv can come from international experience: national and local experience is vital in developing practical and sustainable solutions, and the learning was certainly a two-way process.

The first training programme took place at the Ancient Merv Archaeological Park between 13 and 30 June 2005. It consisted of two courses, the first of which explored the ethics, philosophy and approaches to the management of cultural heritage sites. This was a one-week course aimed at a broad audience recruited from a range of archaeological parks across Turkmenistan (Fig. 2). The course explored trends in the management of cultural heritage, the conservation of earth buildings, approaches to using archaeology in local education, and the balance between conservation and displaying the site to visitors (which included somelively discussions on the role of reconstructions, shelters over excavated archaeological sites, reburying sites to protect them, building visitor centres, training local guides, and the types of guidebooks that might be useful for the local people and international visitors).

The second course looked at approaches to the documentation of cultural heritage sites. This was a two-week course primarily aimed at the Merv park staff, but was also attended by staff from some of the other parks in Turkmenistan. It explored approaches to the recording of archaeological sites, including both buried deposits and standing buildings, and it highlighted the need for good-quality recording to take place prior to conservation work and for archaeologists and conservators to work closely in designing and implementing projects. The course also explored the use of digital and conventional photography for recording monuments, the storage and archiving of records, understanding what is happening to the standing buildings (recording their condition and trying to understand exactly how they are deteriorating), developing conservation action plans, and approaches to reburying old archaeological sites to stop them eroding further. This course also had a strong practical element (see below), aimed at doing something useful for the park.

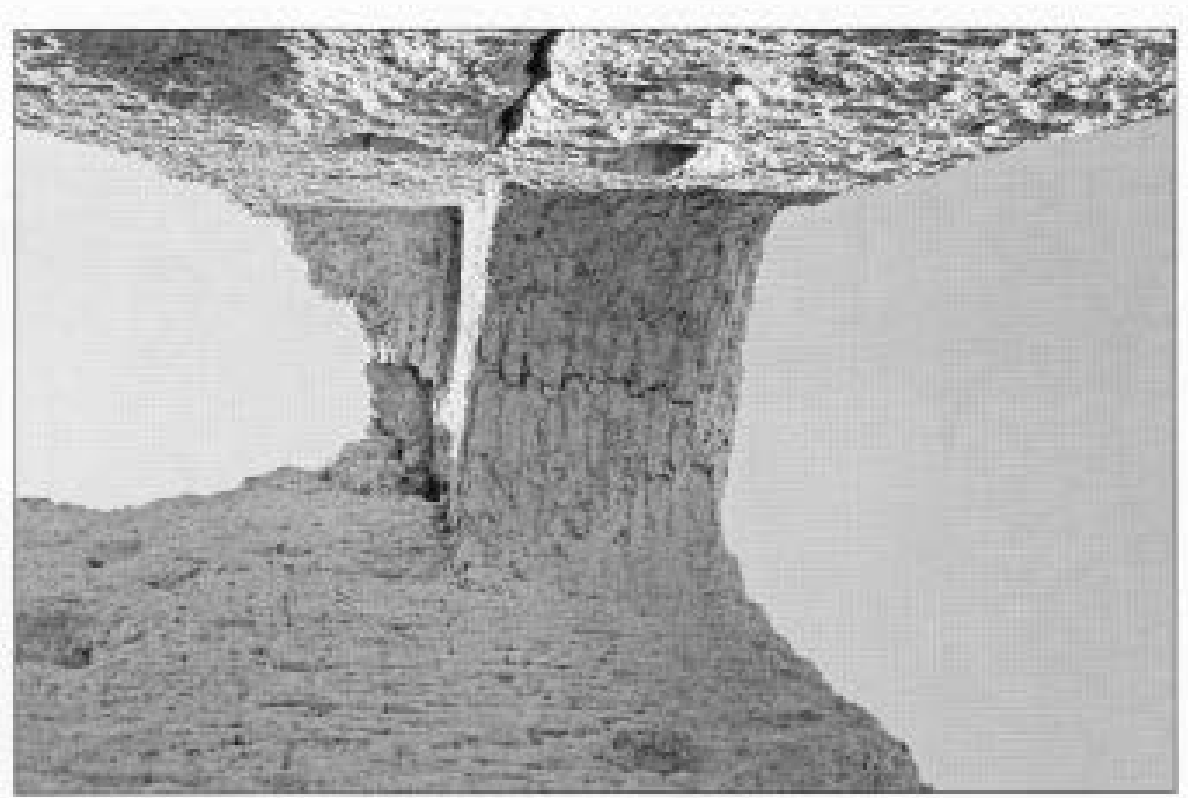

Figure 4 The soaring architecture of Porsy köshk. Not much of this impressive monument survives, although what remains can still be dramatic (photograph taken by Annamyrat Orazow). lems in the next few years and the hole that was undermining the foundation - and fix these as soon as possible. We ranked the severity of these problems for each of the 27 monuments in the core park area and arrived at an agreed priority action list for work.

To do this, it was first necessary for the park staff to undertake assessments of the standing structures. A small köshk, known as Porsy köshk (also known locally as Stinky köshk because of its rather strange ability to attract flies), was selected as an example for thetraining course. The assessment considered information about the building (location, type, date and description), its current condition (Fig. 5), visitor

\section{Working on a köshk}

One of the most common types of standing historic buildings within the park is köshks (Fig. 3). These are large buildings, ranging in size from $100 \mathrm{~m}^{2}$ to $1,000 \mathrm{~m}^{2}$, built of earth, probably mainly during the Sasanian and early Islamic periods, so between the sixth-seventh and eleventh centuries. They were built in the countryside, outside the town walls, and were probably used as fortified houses for the elite, being cool buildings (with their thick mud walls) for people to escape the heat of the city in the long hot summer months. Many of these buildings are now in a very ruinous state, the result of nearly a thousand years of abandonment(Figs 3, 4). In realistic terms, although the park can struggle to preserve as many of these buildings as possible, the task of fully maintaining them all is probably too great. Rather, the aim is to slow down the process, to enable the buildings to survive as long as possible. It was therefore decided that the priority was to identify the elements in each structure that were most at risk - such as the crack that was going to cause major structural prob- 


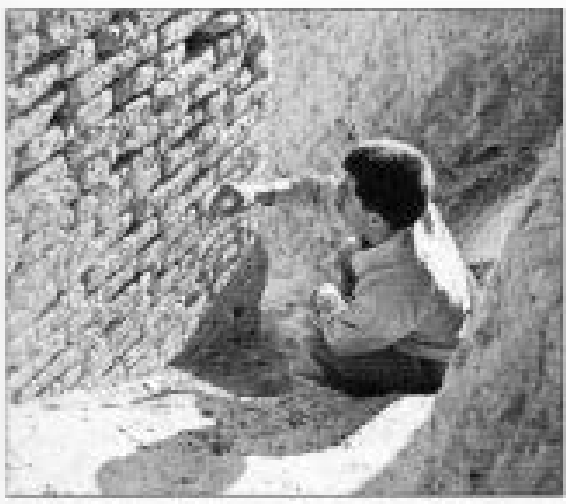

Figure 5 A Turkmen member of staff recording and analyzing mudbrick structures at Porsy köshk.

potential, archaeological significance and risk. This information was then used to prepare proposals for managing the site. The work was undertaken over four mornings in the field, followed by lively afternoon discussions in the park offices. The fieldwork also provided an important opportunity for the participants to experiment with, and gain experience of, digital photography, which was used in the production of the reports. The system developed and refined at Porsy köshk will be used as the basis for the documentation of the other köshks, as part of the park's continuing work programume,

\section{Protecting the entrance to the oldest city}

The oldest city at Merv, Erk Kala, was constructed in about 500 (Fig. 1). In the third century a vast new city was constructed, Antiochia Margiana (known today as Gyaur Kala), extending over nearly $2 \mathrm{~km}$ and covering some $340 \mathrm{ha}$, and the early city was converted into a citadel in the middle of the north wall. The citadel continued to function in one form or another until the Mongol sack of 1221, although in its later life it may have been only a watchtower. There appears to have been only one entrance into the citadel, in the south, and the protection of this has become a concern over recent years. Heavy winter and spring rainfall has started to erode deep drainage gullies, two of which have been cutting down into the fragile buried deposits of the entrance area (Fig. 6), causing substantial damage to this unique part of the city (Figs $7,8)$.

To help develop archaeological recording skills, and approaches to the conservation of earthen slopes, we undertook a cleaning and recording project on the slope as part of the practical element of the training course. The aim was to record the fragile archaeology that had been exposed by the rainwater runoff (Fig. 8), and then to consolidate and repair the wall, packing new earth into the cleaned gulley (after separating it from the unexcavated archaeology with a geotextile), ${ }^{4}$ to protect it from further erosion.

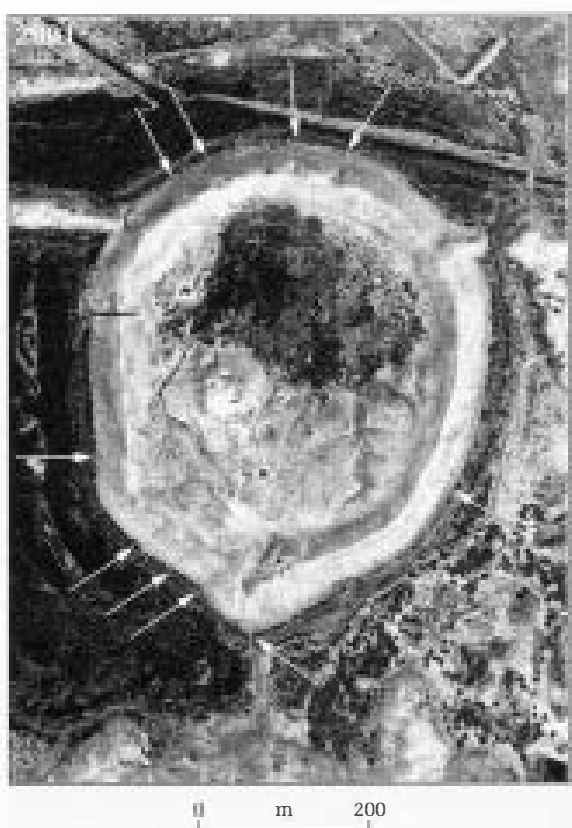

Figure 6 A satellite image of the earliest city at Merv, Erk Kala, showing the major rainwater erosion gullies (indicated by the arrows) and two deep channels in the

entrance area shown (bottom centre of the city wall).

\section{A thousand years of city defences}

The massive city of Gyaur Kala (Fig. 1) was protected in antiquity by a succession of earth defensive walls. The earliest earthwall dates from the third century, with later additions strengthening the thickness and height of the walls, as well as adding new walkways, parapets, arrow slits and bastions. Amazingly, the sequence of walls from the third century to the fifth century survives virtually intact for the $8 \mathrm{~km}$ of the city circuit. The last earthwalls, probably dating from the seventh-eighth centuries, have been gradually eroded by the rain and wind, and the debris from these formed the earthbank that the visitor sees today.

A sequence was excavated through these defensive walls between 1999 and 2004 (Fig. 9). It was considered important that this informative sequence should be left
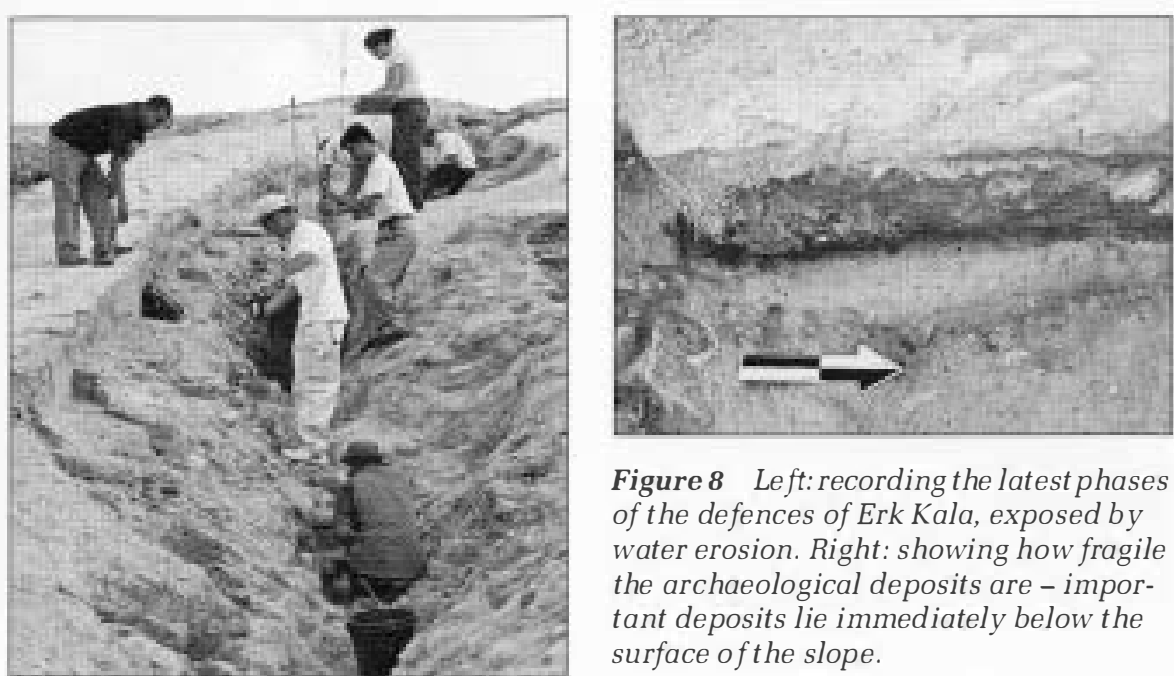

Figure 8 Left:recording the latest phases of the defences of Erk Kala, exposed by water erosion. Right: showing how fragile the archaeological deposits are - important deposits lie immediately below the surface of the slope. 


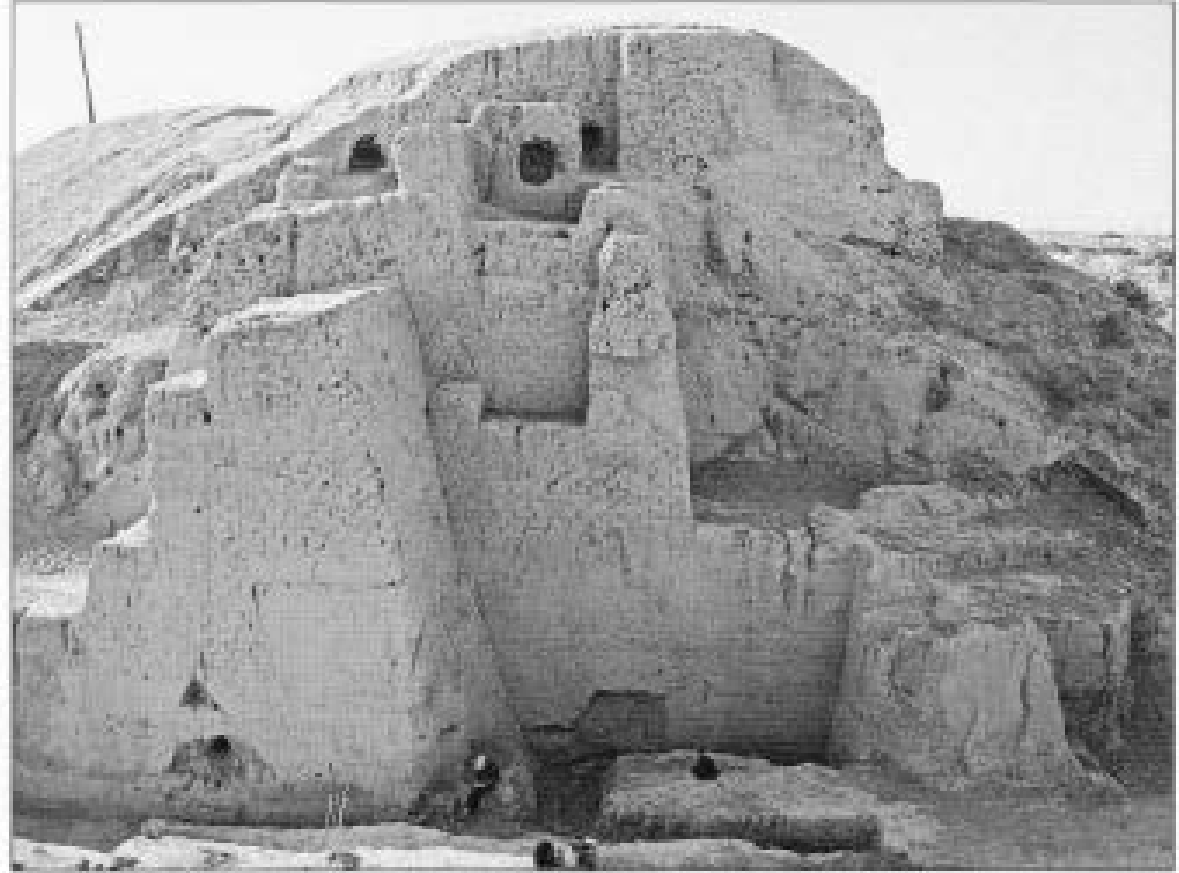

Figure 9 A section across the defences of the city of Gyaur Kala - an impressive thousand-year sequence of military architecture.

exposed so that visitors to the site could see this sequence, because it evocatively captures the development of the cities and their empires. The problem is how to conserve an earthen section standing some $25 \mathrm{~m}$ high. The decision was to develop a maintenance programme, observing the wall each year after the rains, cleaning and repairing - especially filling small cracks before they develop into structurally damaging ones - and managing the rainfall runoff channels. To this end the park staff have implemented a rigorous system of annual documentation (Fig. 10) and they ensure that the small-scale repairs are undertaken. $^{5}$

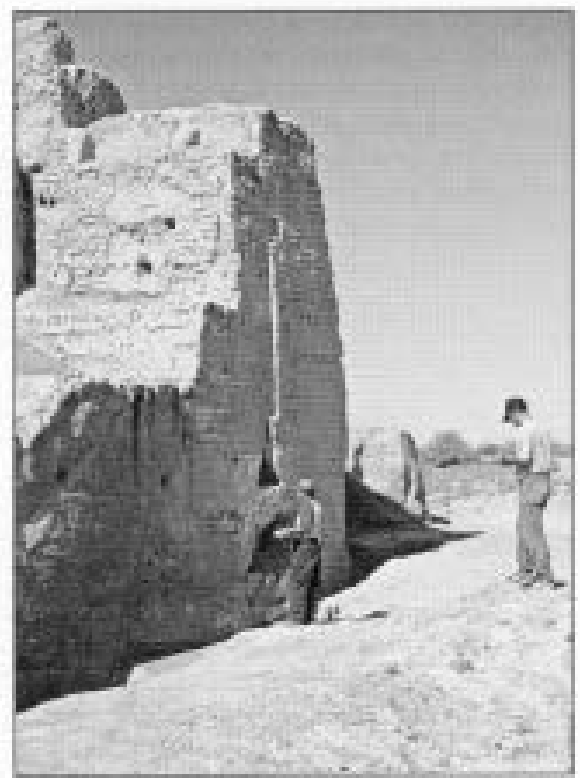

Central Asian countries, to promote the exchange of best practice and new techniques across the region. Existing crossborder initiatives, such as the Central Asian Earth Programme sponsored by UNESCO, need to be developed with more active representation and participation if they are to act as a platform for sharing experiences.

Developing of specialist training programmes in new techniques: There is a need to develop programmes, not just for Merv but for other parks as well, to support the implementation of new techniques. An example might be the use of 3-D laser scanning to record standing buildings, both in advance of conservation or restoration and also to create a high-quality long-term record of the structures.

Conservation and archaeological agendas and protocols: developing dialogue over procedures, practice and implementation. At present we are writing an archaeological recording manual, specific to the needs of the archaeological work at Merv and Turkmenistan, which is being translated into Turkmen.

Digital monument passports: The Ministry of Culture currently operates a monument passport system, which provides a paper record of each archaeological monument (its history and current condition). This could easily be computerized, which would help to save time when updating the monument information, making it easier to build upon a platform of past work. A pilot project is being developed by the Institute of Archaeology.

Interpretive material: Priorities for action were discussed and different types of information were envisaged for the park: navigational information to guide visitors around the vast site, a guidebook with more detailed information for local and foreign visitors, and a more substantial illustrated guide to the site and its context

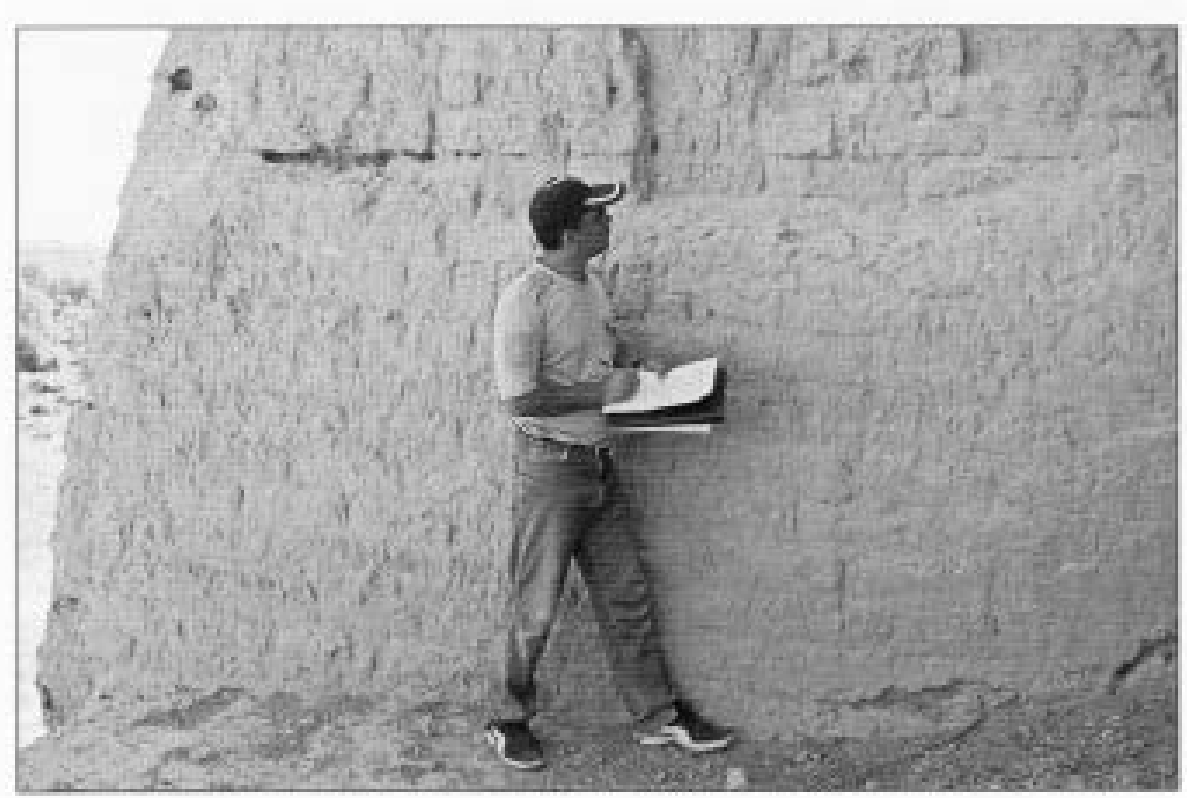

Figure 10 Turkmen Parkstaff undertaking monitoringand recording activities at the Gyaur Kala defences, in advance of conservation. 
(for sale at the site and elsewhere). In addition, interpretation is needed at specific monuments. This will include signs (containing information, historic pictures, plans and reconstructions), information packs designed for guides and those leading tour groups (with quantities of visual and written information for each of the monuments), and packs for independent visitors. The longer-term vision is to construct new parkbuildings to provide facilities for visitors and park activities, such as archiving, research and conservation.

Shelters for the display of excavated archaeological sites: Excavated remains in the area are fragile, of ten made mostly of earth (e.g. mudbrick), and very susceptible to erosion by wind, rain and rising damp. However, the park wants to be able to display some of this material to the visitor. The feasibility of using modern shelters to protect these archaeological remains is being explored, especially the possibility of using temporary seasonal shelters to protect the sites from the most damaging winter and spring rains, while enabling them to be removed before the main visitor season and thus reducing their visual impact on the landscape at that time.

The park boundary: There are many issues surrounding the current boundary of the Archaeological Park and the slightly different boundary of the World Heritage Site. Important suburban areas are not currently protected (e.g. the area of the city of Shaim Kala) and there are also damaging incursions into the area by modern burial grounds.

Literature, libraries and a glossary: It was clear that more background and technical information, preferably translated into Turkmen, needed to be available to the park staff to support their work. Work is already under way on developing a glossary of conservation, archaeological and architectural terms, in Turkmen, Russian and English, to help improve the exchange of ideas.

Training/support in archive management: There is an urgent need to develop expertise in the management of the material held by the Archaeological Park. The park has large quantities of archaeological objects, architectural material, paper and computer-based records, and photographic archives. The park is committed to looking after its holdings and a new member of staff has recently appointed to focus on this issue, but they need help to develop appropriate systems for the harsh Central Asian environment.

\section{And now}

As the above shows, much remains to be done. Developing the exchange of experience and cooperation between experts and organizations of Central Asian countries, for the protection and conservation of cultural heritage, is a major priority for all of us concerned with the cultural heritage of this significant region. The Institute of
Archaeology, as part of the wider international community, will continue to develop opportunities for building capacity (people, skills, equipment and resources) in Turkmenistan, both through our projects and by undertaking wider professional training programmes. In practical terms, we need to provide more training and development opportunities if this is to be a sustainable exchange, and we urgently need to find more resources to build upon the successes of the first programme.

\section{Notes}

1. See G. Herrmann in Archaeology International 1997/1998,32-6, for a resumé of the setting and development of the cities.

2. See T. Williams in Archaeology International 2002/2003, 40-43, for an introduction to the current project.

3. This work was generously funded and enabled by a grant from the Kaplan Foundation, with the support and administration of the World Monuments Fund. Special thanks got to Gaetano Palumbo and Mark Webber for their support throughout this project. Thanks also to UNESC and CraTerre-EAG (especially Sébastien Moriset and David Gandreau) for their participation in the training programmes, and to Dr Mamedov for coordinating the Ministry ofCulture input, Rejeb Jepbarow for his organization at the Ancient Merv Park, Louise Cooke (UCL) for her excellent and unflagging work on the training programme, Gaigysyz Joraev for his excellent simultaneous translation (between Turkmen, Russian and English), Nikki Harriss (UCL) for all her hard work coordinating the Erk Kala programme, and most of all to the participants who devoted their energy and enthusiasm to the project: Rejeb Jepbarow, Murat Hojaowezow, Annamyrat Orazow, Merdan Jumanazarow, Jumageldy Pirliew, Perman Dowrangeldiew, Igor Zubanov, Maksat Hojammayew, Rada Denega, Arslan Mamedov, and Mekan Annanurow.

4. Geotextiles are synthetic fabrics, usually woven, which are durable and permeable to water.

5. Special thanks to Louise Cooke and Nathalie Peek, who developed the system with the park staff. 